\title{
Características físicas e químicas de ovos comerciais de codornas das linhagens japonesa e americana
}

\author{
Physical and chemical characteristics of commercial eggs \\ from Japanese and American quails breeds
}

Dyego da Costa Santos ${ }^{[a]}$, Emanuel Neto Alves de Oliveira ${ }^{[a]}$, Jeane Karla de Mendonça Mota ${ }^{[b]}$, Renilson Targino Dantas ${ }^{[c]}$, Joana Paula Nascimento Peixoto[d]

[a] Tecnólogo em alimentos, mestrando em Engenharia Agrícola pela Universidade Federal de Campina Grande (UFCG), Campina Grande, PB - Brasil, e-mail: dyego.csantos@gmail.com; emanuelnetoliveira@ig.com.br

[b] Zootecnista, doutoranda em Engenharia Agrícola pela Universidade Federal de Campina Grande (UFCG), Campina Grande, PB - Brasil, e-mail: motajkm@yahoo.com.br

[c] Meteorologista, Doutor em Agronomia. professor da Universidade Federal de Campina Grande (UFCG), Campina Grande, PB - Brasil, e-mail: renilson@dca.ufcg.edu.br

[d] Zootecnista, Mestre em Engenharia Agrícola pela Universidade Federal de Campina Grande (UFCG), Campina Grande, PB Brasil, e-mail: jpnpeixoto@hotmail.com

\section{Resumo}

O objetivo do estudo foi avaliar a qualidade física e química de ovos de codorna japonesa e americana. Cem ovos de codorna (50 unidades de cada linhagem) foram analisados quanto aos parâmetros de massa individual, diâmetros longitudinal e transversal, cor (luminosidade e cromaticidade), pH, acidez, atividade de água e proteína, com avaliação da clara, gema e mix (mistura da clara e gema). Verificou-se que as maiores massas individuais foram encontradas nos ovos de codorna americana $(13,56 \pm 0,91 \mathrm{~g})$ e, consequentemente, também os maiores diâmetros transversal $(26,79 \pm 0,77 \mathrm{~mm})$ e longitudinal $(35,18 \pm 1,20 \mathrm{~mm})$. Quanto à cor, a maior intensidade de luminosidade ( $\mathrm{L}^{*}$ ) foi constatada na clara e as maiores intensidades de vermelho $\left(+\mathrm{a}^{*}\right)$ e amarelo $\left(+\mathrm{b}^{*}\right)$ na gema e $m i x$, respectivamente, com diferença significativa entre as linhagens. Os maiores teores de acidez e $\mathrm{pH}$ foram observados nas gemas e claras, respectivamente, com diferença significativa entre ambos os ovos. Além disso, verificou-se atividade de água superior a 0,98 nos ovos, evidenciando sua necessidade de refrigeração. Os maiores teores de proteínas foram revelados na gema e os menores na clara, para ambos os ovos, com diferença significativa a 5\% de probabilidade entre as linhagens. Diante dos resultados, conclui-se que existem diferenças significativas entre as características físicas e químicas de ovos de codorna japonesa e americana.

Palavras-chave: Ovo de codorna. Qualidade. Proteína. 


\section{Abstract}

The objective of this study was to evaluate the physical and chemical quality of quail eggs (Japanese and American). A hundred quail eggs (50 units of each breed) were analyzed for individual mass, longitudinal and transverse diameters, color (luminance and chromaticity), $p H$, acidity, water activity and protein, with assessment of albumen, yolk and mixture (mixture of albumen and yolk). The largest individual mass was found in the American quail eggs (13.56 $\pm 0.91 \mathrm{~g})$ and, consequently, also the largest cross-sectional (26.79 $\pm 0.77 \mathrm{~mm})$ and longitudinal (35.18 $\pm 1.20 \mathrm{~mm}$ ) diameters. As for color, the greater intensity of lightness $\left(L^{*}\right)$ was observed in the albumen, while the highest levels of redness $\left(+a^{*}\right)$ and yellowness $\left(+b^{*}\right)$ were found in the yolk and mix, respectively. The highest levels of acidity and $\mathrm{pH}$ were noticed in the yolk and albumen, respectively, with significant difference between eggs of different breeds. The highest levels of proteins were encountered in the yolk and the lowest in the albumen, for both types of eggs, with a significant difference ( $p<0.05)$ among breeds. Overall, these experiments were able to demonstrate significant differences between the physical and chemical characteristics of Japanese and American quail eggs.

Keywords: Quail eggs. Quality. Protein.

\section{Introdução}

A coturnicultura é uma atividade avícola em expansão, responsável pela geração de emprego e renda em todos os níveis de sua cadeia produtiva. Além disso, seu principal produto, o ovo, é uma fonte de proteína animal de alto valor biológico (MOURA et al., 2010a).

Praticamente em todas as culturas, os ovos têm sido apreciados tanto por suas propriedades nutritivas quanto funcionais. Nas sociedades ocidentais, o maior consumo se dá para ovos de galinha, porém isso está se modificando e os ovos de codornas estão ganhando mercado, principalmente em restaurantes, como acompanhamento de diferentes pratos (SEIBEL et al., 2005). Segundo Piccinin et al. (2005), o consumo de ovos de codorna tem aumentado em função da utilização crescente por restaurantes e buffets.

Além de ser um alimento completo e equilibrado em nutrientes, o ovo é uma fonte de proteína de baixo valor econômico, podendo contribuir para melhorar a dieta de famílias de baixa renda (LEANDRO et al., 2005). Segundo Panda e Singh (1990), o ovo de codorna apresenta teor médio de $74,6 \%$ de umidade, $13,1 \%$ de proteína, $11,2 \%$ de lipídios e 1,1\% de minerais. De acordo com Albino e Barreto (2003), esses ovos apresentam uma proteína de elevado índice de digestibilidade.

A clara representa cerca de $60 \%$ do peso do ovo, sendo rica em água e proteínas, principalmente a albumina. A gema, responsável por $30-32 \%$ do peso total, é formada basicamente por água, proteínas e lipídios (SALVADOR; SANTA, 2002). As proteínas da clara e da gema possuem capacidade de se coagularem e funcionarem como uma espécie de ligação entre outros ingredientes (VADEHRA; NATH, 1973; MINE, 1995;). Segundo Sgarbieri (1996), a clara e suas proteínas são utilizadas principalmente na manufatura de produtos de baixa densidade e de elevada expansibilidade, em virtude da capacidade que essas proteínas têm de incorporar ar e formar espumas.

Para Lucotte (1976), a cor e o desenho dos ovos são dependentes da genética da ave e variam demasiadamente de uma poedeira para outra, podendo ser claro, amarelo, marrom claro, esverdeado ou escuro, e ter manchas marrons escuras ou negras, que podem ser pequenas, médias ou grandes. Seu peso mede em torno de $10 \mathrm{~g}$, podendo oscilar bastante, chegando a pesar $15 \mathrm{~g}$, medida que varia de acordo com a alimentação, a temperatura ambiente e a idade da codorna.

A cor da gema é comumente relacionada à qualidade nutricional do ovo e, muitas vezes, é ferramenta decisória para a aquisição do produto pelo consumidor. Porém, o sabor é a característica sensorial que determina a preferência do consumidor pelo produto em questão (MOURA et al., 2009). Segundo Hencken (1992), a cor da gema depende da presença de componentes carotenoides na dieta das aves e, quanto mais as aves consumirem alimentos que 
contenham pigmentos carotenoides em sua constituição, maior será a deposição desses pigmentos nas gemas dos ovos e a intensidade da sua coloração.

Segundo Freitas et al. (2011), o aumento do consumo de ovos e a utilização de seus benefícios nutricionais pela população dependem da qualidade do produto oferecido ao consumidor, determinada por um conjunto de características que podem influenciar o seu grau de aceitabilidade no mercado e agregar preço ao produto.

A fim de que se assegure a qualidade dos ovos expostos ao consumo público, é necessário que os mesmos sejam submetidos à inspeção por órgão oficial, o que é exigido pelo Regulamento da Inspeção Industrial e Sanitária de Produtos de Origem Animal (RIISPOA), que atua inspecionando desde o recebimento até a expedição dos ovos frescos, ou seja, não conservados por qualquer processo, desde que se enquadrem aos exames e classificação estabelecidos no RIISPOA (BRASIL, 1997; BAPTISTA, 2002;).

Alguns estudos investigaram a qualidade de ovos. Souza e Souza (1995) pesquisaram o efeito da temperatura de estocagem sobre a qualidade interna de ovos de codorna armazenados durante 21 dias. Leandro et al. (2005) estudaram aspectos de qualidade interna e externa de ovos comercializados em diferentes estabelecimentos na região de Goiânia. Piccinin et al. (2005) investigaram técnicas de conservação da qualidade de ovos de codornas. Seibel et al. (2005) pesquisaram a qualidade física e química de ovos de codornas alimentadas com dietas modificadas. Carvalho et al. (2007) optaram por pesquisar a qualidade interna e da casca de ovos. Costa et al. (2008) pesquisaram a influência do óleo de linhaça sobre a qualidade de ovos. Moura et al. (2009) estudaram as características sensoriais de ovos de codornas japonesas suplementadas com pigmentantes sintéticos e selenometionina. Sobral et al. (2009) caracterizaram o consumidor de ovos de codorna no município de Patos-PB. Moura et al. (2010) estudaram a qualidade do ovo de codornas japonesas alimentadas com rações contendo sorgo. Freitas et al. (2011) investigaram os aspectos qualitativos de ovos comerciais submetidos a diferentes condições de armazenamento.

Diante do exposto, o objetivo deste trabalho foi avaliar as qualidades físicas e químicas de ovos comerciais de codorna japonesa (Coturnix coturnix japonica) e americana (Calinus virginianus).

\section{Materiais e métodos}

\section{Obtenção dos ovos}

A pesquisa foi desenvolvida no primeiro semestre de 2011, com coleta aleatória de 100 ovos de codornas das linhagens japonesa e americana (50 ovos de cada linhagem), em um galpão de codornas de postura localizado em João Pessoa-PB (altitude de $20 \mathrm{~m}$, latitude de $07^{\circ} 18^{\prime} 34^{\prime \prime} \mathrm{S}$ e longitude de $34^{\circ}$ 84' 89" 0). De acordo com a classificação climática de Koeppen, o clima da região é tropical e a temperatura média anual é de $26^{\circ} \mathrm{C}$. Ambas as codornas receberam a mesma alimentação, sendo constituída de ração à base de milho.

\section{Caracterização física e química dos ovos}

Os ovos foram transportados e analisados no Laboratório de Armazenamento e Processamento de Produtos Agrícolas (LAPPA) da Unidade Acadêmica de Engenharia Agrícola (UAEA), do Centro de Tecnologia e Recursos Naturais (CTRN) da Universidade Federal de Campina Grande (UFCG), na cidade de Campina Grande-PB.

Após a recepção no laboratório, os ovos foram submetidos à lavagem, com a finalidade de remover possíveis resíduos aderidos, utilizando-se detergente de grau alimentício. Em seguida, os ovos foram enxaguados em água corrente e secos com papel toalha.

Os ovos de codorna foram pesados individualmente, em balança analítica com precisão 0,001 g, e tiveram os diâmetros longitudinal (a) e transversal (b) medidos com o auxílio de um paquímetro digital. Nas etapas subsequentes, foram avaliadas as características físicas e químicas da clara, gema e mix (mistura da clara e gema) dos ovos. $\mathrm{Na}$ preparação das amostras, foram separadas a clara e a gema dos ovos, e na preparação do mix, os ovos foram quebrados, e a clara e a gema transferidas, na sua totalidade, para um béquer, sendo homogeneizados em seguida.

A determinação da cor foi realizada com a utilização de espectrofotômetro portátil Hunter Lab Mini Scan XE Plus, modelo 4.500 L, com obtenção dos parâmetros $\mathrm{L}^{*}, \mathrm{a}^{*}$ e $\mathrm{b}^{*}$, onde $\mathrm{L}^{*}$ define a luminosidade $\left(L^{*}=0\right.$ - preto e $L^{*}=100$ - branco) e $a^{*}$ e $b^{*}$ 
são responsáveis pela cromaticidade $\left(+\mathrm{a}^{*}\right.$ vermelho e $-a^{*}$ verde; $+b^{*}$ amarelo e $-b^{*}$ azul).

A medida da atividade de água (Aw) foi realizada por meio da utilização do equipamento Aqualab modelo 3TE, da Decagon Devices. De acordo com Ferreira e Pena (2003), a atividade de água $(\mathrm{Aw})$ é uma medida da quantidade de moléculas de água livres ou ativas, geralmente obtida em relação à pressão de vapor da água pura. A possibilidade de alteração microbiana em alimentos acaba naqueles que apresentam Aw abaixo de 0,60 , embora isso não signifique a destruição dos microrganismos.

0 potencial hidrogeniônico $(\mathrm{pH})$ foi determinado segundo o método eletrométrico. 0 potenciômetro utilizado era da marca Analyser modelo PH-300M, previamente calibrado com soluções tampões de pH 7,0 e 4,0. Hoffmann (2001) afirma que o potencial hidrogeniônico mede a concentração de $\mathrm{H}^{+}$de um alimento ou solução e é geralmente representado pela equação: $\mathrm{pH}=\log 1 /\left[\mathrm{H}^{+}\right]$. De acordo com ela, observa-se que quanto mais elevada a concentração de $\mathrm{H}^{+}$(caráter ácido), menor é o $\mathrm{pH}$. Assim, o pH é menor em alimentos ácidos. $0 \mathrm{pH}$ varia de 0 a 14 , sendo 7 o valor que expressa a neutralidade.

A acidez foi determinada pelo método titulométrico. Nesta metodologia, a amostra foi dissolvida em água destilada e titulada com solução de hidróxido de sódio a $0,1 \mathrm{~N}$ até viragem para rósea clara. 0 ponto de viragem foi verificado em virtude da utilização de solução indicadora de fenolftaleína. De acordo com o Instituto Adolfo Lutz (2008), a acidez fornece um dado valioso na apreciação do estado de conservação de um produto alimentício, pois num processo de decomposição, seja por hidrólise, oxidação ou fermentação, a concentração de ácido apresenta-se quase sempre alterada, revelando, assim, seu estado atual de conservação na medição dessa concentração.

0 teor de proteína foi determinado pelo método micrométrico Kjeldahl dividido em três etapas: digestão da amostra em ácido sulfúrico concentrado e mistura catalítica; destilação da mistura obtida da digestão em destilador de nitrogênio; titulação do destilado com solução de ácido clorídrico a $0,1 \mathrm{~N}$, de acordo com metodologia preconizada pela Association of Official Analytical Chemists (AOAC, 1995).

\section{Análise estatística}

O delineamento experimental das análises físicas dos ovos foi o de blocos inteiramente casualizados com dois tratamentos e 50 repetições, utilizando-se o software Assistat. Os dados foram submetidos à análise de variância (ANOVA) e a comparação de médias foi feita pelo teste de Tukey em nível de 5\% de probabilidade. Para as análises físico-químicas, foi utilizado o mesmo delineamento experimental utilizando três repetições.

\section{Resultados e discussão}

Estão apresentados nas Tabelas de 1 a 5 os resultados das análises físicas e químicas dos ovos de codornas das espécies japonesa e americana.

Observa-se que a massa média dos ovos de codorna americana foi de 13,56 $\pm 0,91 \mathrm{~g}$ (Tabela 1) apresentando-se superior à massa média dos ovos de codorna japonesa $(10,70 \pm 1,02)$, dados que demonstram haver uma diferença significativa entre as massas médias dos ovos, em nível de $1 \%$ de probabilidade. Seibel e Soares (2004) encontraram massa média de $11,56 \pm 0,82 \mathrm{~g}$ para ovos de codorna japonesa. Já Moura et al. (2010a) verificaram massa de ovos de codorna japonesa variando entre $11,63 \pm 0,53$ e 12,02 $\pm 0,17 \mathrm{~g}$; e Moura et al. (2010b) encontraram massa de ovos de codorna japonesa compreendida entre 10,97 e 11,42 g.

Ao se analisar o diâmetro dos ovos, observa-se que os ovos de codorna americana apresentaram os maiores valores e, portanto, a maior massa individual média. Verificou-se que os ovos de codorna americana apresentaram diâmetros longitudinal e transversal médios de 35,18 $\pm 1,20 \mathrm{~mm}$ (variação compreendida entre 33,00 e $37,50 \mathrm{~mm}$ ) e $26,79 \pm$ $0,77 \mathrm{~mm}$ (variação compreendida entre 25,8 e 28,9 $\mathrm{mm}$ ), respectivamente. Entretanto, para os ovos de codorna japonesa, foram verificados diâmetros longitudinal e transversal de $31,96 \pm 2,42 \mathrm{~mm}$ (variação compreendida entre 29,50 e $35,50 \mathrm{~mm}$ ) e 24,45 $\pm 2,32 \mathrm{~mm}$ (variação compreendida entre $22,90 \mathrm{e}$ 25,90 mm), respectivamente. Os diâmetros dos ovos revelaram diferença estatística em nível de $1 \%$ de probabilidade.

No tocante à cor, a maior intensidade de luminosidade $\left(L^{*}\right)$ foi verificada na clara, para ambos os ovos. 
As maiores intensidades de vermelho $\left(\mathrm{a}^{*}\right)$ e amarelo $\left(b^{*}\right)$ foram observadas na gema e mix, respectivamente, para as duas espécies de codorna. Observa-se que, para a clara, a cromaticidade $\left(a^{*}\right)$ foi negativa, confirmando a ausência de tonalidade vermelha (Tabela 2). Nota-se, ainda, que houve diferença significativa, em nível de $1 \%$ de probabilidade, para as amostras estudadas (clara, gema e mix) quanto aos parâmetros avaliados para a determinação de cor.

Segundo Moura et al. (2010a), o ovo de codorna geralmente é consumido cozido e inteiro, ao contrário do ovo de galinha, que é submetido à cocção, fritura ou processamento pela indústria alimentícia. Isso torna a cor da gema do ovo de codorna um atributo de importância econômica secundária ou de pouca relevância.

Observa-se que a acidez das gemas dos ovos de codorna americana e japonesa foram de 0,43 $\pm 0,01$ e $0,41 \pm 0,01$, respectivamente, superiores à acidez do mix (Tabela 3). Isso é justificado, pois a clara apresenta característica básica e, misturada com a gema, tende a diminuir a acidez.

Quanto ao $\mathrm{pH}$, a clara dos ovos apresentou valores de 9,31 $\pm 0,01$ (codorna americana) e 9,38 $\pm 0,01$ (codorna japonesa), ao passo que a gema apresentou pH inferior a 7,00 (Tabela 3). Souza e Souza (1995) encontraram valores semelhantes de $\mathrm{pH}$ para a clara $(9,02$ e 8,98$)$ e gema $(6,14$ e 6,12$)$ ao estudarem

Tabela 1 - Resultados das análises físicas de ovos de codorna das espécies americana e japonesa

\begin{tabular}{lccc}
\hline & & \multicolumn{2}{c}{ Diâmetro médio (mm) } \\
\cline { 3 - 4 } Amostra & Massa $(\mathbf{g})$ & Longitudinal (a) & Transversal (b) \\
\hline Americana & $13,56^{\mathrm{a}} \pm 0,91$ & $35,18^{\mathrm{a}} \pm 1,20$ & $26,79^{\mathrm{a}} \pm 0,77$ \\
Japonesa & $10,70^{\mathrm{b}} \pm 1,02$ & $31,96^{\mathrm{b}} \pm 2,42$ & $24,45^{\circ} \pm 2,32$ \\
\hline MG & 12,13 & 33,57 & 25,62 \\
DMS & 0,62 & 0,84 & 1,11 \\
CV (\%) & 7,95 & 3,92 & 6,74 \\
Fcal. & $87,84^{*}$ & $59,98^{*}$ & $18,35^{*}$ \\
\hline
\end{tabular}

Fonte: Dados da pesquisa.

Legenda: MG = Média geral; DMS = Diferença mínima significativa; CV = Coeficiente de variação; \pm = Desvio padrão; Fcal = F calculado. Médias seguidas de letras diferentes na coluna diferem estaticamente a $5 \%$ de probabilidade pelo teste de Tukey; ${ }^{*}=$ significativo a $1 \%$ de probabilidade pelo teste $\mathrm{F}$.

Tabela 2 - Resultados da análise cor de ovos de codorna das espécies americana e japonesa

\begin{tabular}{|c|c|c|c|c|c|c|c|c|c|}
\hline \multirow[b]{2}{*}{ Amostra } & \multicolumn{3}{|c|}{ Clara } & \multicolumn{3}{|c|}{ Gema } & \multicolumn{3}{|c|}{ Mix } \\
\hline & $\mathbf{L}^{*}$ & $-a^{*}$ & $+b^{*}$ & $\mathbf{L}^{*}$ & $+a^{*}$ & $+b^{*}$ & $\mathbf{L}^{*}$ & $+a^{*}$ & $+b^{*}$ \\
\hline Americana & $36,06^{a}$ & $-2,16^{a}$ & $34,23^{a}$ & $34,49^{a}$ & $4,59^{a}$ & $41,34^{a}$ & $34,70^{a}$ & $0,70^{\mathrm{a}}$ & $34,50^{\mathrm{a}}$ \\
\hline Japonesa & $33,76^{b}$ & $-1,58^{b}$ & $33,52^{b}$ & $33,02^{b}$ & $3,83^{b}$ & $39,10^{\mathrm{b}}$ & $30,07^{\mathrm{b}}$ & $0,30^{b}$ & $31,50^{b}$ \\
\hline MG & 34,91 & $-1,87$ & 33,88 & 33,76 & 4,21 & 40,22 & 32,38 & 0,50 & 33,00 \\
\hline DMS & 0,34 & 0,25 & 0,34 & 0,52 & 0,17 & 0,35 & 2,40 & 0,23 & 0,45 \\
\hline CV (\%) & 0,43 & 5,84 & 0,44 & 0,68 & 1,77 & 0,38 & 3,26 & 20,00 & 0,61 \\
\hline Fcal. & $350,59^{* *}$ & $41,86^{* *}$ & $33,19^{* *}$ & $60,87^{* *}$ & $154,28^{* *}$ & $319,82^{* *}$ & $28,84^{* *}$ & $24,00^{* *}$ & $337,50^{* *}$ \\
\hline
\end{tabular}

Fonte: Dados da pesquisa.

Legenda: MG = Média geral; DMS = Desvio médio significativo; CV = Coeficiente de variação; \pm = Desvio padrão; Fcal = F calculado. Médias seguidas de letras diferentes na coluna diferem estaticamente a $5 \%$ de probabilidade pelo teste de Tukey; ns = não significativo, ${ }^{*}=$ significativo a $5 \%,{ }^{* *}=$ significativo a $1 \%$ de probabilidade pelo teste $\mathrm{F}$. 
Tabela 3 - Análises de acidez e pH de ovos de codorna das espécies americana e japonesa

\begin{tabular}{lccccccc}
\hline & \multicolumn{3}{c}{ Acidez (\%) } & & \multicolumn{2}{c}{ pH } \\
\cline { 2 - 3 } \cline { 6 - 7 } Amostra & Gema & Mix & Clara & & Gema & Mix \\
\hline Americana & $0,43^{\mathrm{a}} \pm 0,01$ & $0,15^{\mathrm{a}} \pm 0,00$ & $9,31^{\mathrm{b}} \pm 0,01$ & & $5,99^{\mathrm{b}} \pm 0,03$ & $7,54^{\mathrm{a}} \pm 0,03$ \\
Japonesa & $0,41^{\mathrm{a}} \pm 0,01$ & $0,14^{\mathrm{a}} \pm 0,01$ & $9,38^{\mathrm{a}} \pm 0,01$ & & $6,22^{\mathrm{a}} \pm 0,01$ & $7,54^{\mathrm{a}} \pm 0,03$ \\
\hline MG & 0,42 & 0,15 & 9,35 & & 6,10 & 7,54 & 0,07 \\
DMS & 0,02 & 0,01 & 0,02 & & 0,04 & 0,42 \\
CV (\%) & 2,56 & 3,53 & 0,09 & & 0,31 & $0,00^{\text {ns }}$ \\
Fcal. & $5,50^{\text {ns }}$ & $1,60^{\text {ns }}$ & $121,00^{*}$ & & $222,73^{*}$ & & \\
\hline
\end{tabular}

Fonte: Dados da pesquisa.

Legenda: $\mathrm{MG}$ = Média geral; DMS = Desvio médio significativo; $\mathrm{CV}$ = Coeficiente de variação; \pm = Desvio padrão; $\mathrm{Fcal}$ = F calculado. Médias seguidas de diferentes letras na coluna diferem estaticamente a $5 \%$ de probabilidade, pelo teste de Tukey; $n \mathrm{~s}=$ não significativo, ${ }^{*}=$ significativo a $1 \%$ de probabilidade, pelo teste $\mathrm{F}$.

ovos de codorna japonesa, e Baptista (2002) verificou o $\mathrm{pH}$ da clara e gema de ovos de codorna japonesa de 9,23 e 6,06, respectivamente. Já Leandro et al. (2005) verificaram o $\mathrm{pH}$ da clara de ovos de galinha variando de 8,04 a 9,48, e o $\mathrm{pH}$ da gema variando de 6,26 a 6,38. Alleoni e Antunes (2005) verificaram $\mathrm{pH}$ da clara de ovos de galinha frescos como 7,93.

A atividade de água da clara, gema e mix apresentaram valores superiores a 0,98 , sendo revelados os maiores e menores valores na clara dos ovos de codorna americana $(0,9960 \pm 0,00)$ e gema dos ovos de codorna

Tabela 4 - Análises de atividade de água de ovos de codorna das espécies americana e japonesa

\begin{tabular}{lccc}
\hline & \multicolumn{3}{c}{ Aw } \\
\cline { 2 - 4 } Amostra & Clara & Gema & Mix \\
\hline Americana & $0,9960^{\mathrm{a}} \pm 0,0004$ & $0,9922^{\mathrm{a}} \pm 0,0016$ & $0,9919^{\mathrm{a}} \pm 0,0056$ \\
Japonesa & $0,9949^{\mathrm{a}} \pm 0,0012$ & $0,9851^{\mathrm{b}} \pm 0,0033$ & $0,9920^{\mathrm{a}} \pm 0,0032$ \\
\hline MG & 0,9954 & 0,9886 & 0,9920 \\
DMS & 0,01 & 0,01 & 0,0104 \\
CV (\%) & 0,09 & 0,26 & 0,4602 \\
Fcal. & $1,97^{\text {ns }}$ & $11,14^{*}$ & $0,0007^{*}$ \\
\hline
\end{tabular}

Fonte: Dados da pesquisa.

Legenda: MG = Média Geral; DMS = Desvio médio significativo; CV = Coeficiente de variação; \pm = Desvio padrão; Fcal = F calculado. Médias seguidas de diferentes letras na coluna diferem estaticamente a $5 \%$ de probabilidade, pelo teste de Tukey; ns = não significativo, ${ }^{*}=$ significativo a 5\%, pelo teste $F$. japonesa $(0,9851 \pm 0,00)$, respectivamente (Tabela 4$)$. Esses resultados evidenciam a necessidade de refrigeração para ovos de codorna, uma vez que apresentam grande quantidade de água disponível para o desenvolvimento microbiano.

Os maiores teores de proteínas foram revelados na gema $(14,64 \pm 0,30 \mathrm{~g} / 100 \mathrm{~g}$ para ovos de codorna americana e 14,18 $\pm 0,10 \mathrm{~g} / 100 \mathrm{~g}$ para ovos de codorna japonesa), seguidos por mix e clara (Tabela 5). Verifica-se que houve diferença significativa dos teores de proteínas, em nível de 5\% de significância,

Tabela 5 - Análise de proteína de ovos de codorna das espécies americana e japonesa

\begin{tabular}{lccc}
\hline & \multicolumn{3}{c}{ Proteína (g/100 g) } \\
\cline { 2 - 4 } Amostra & Clara & Gema & Mix \\
\hline Americana & $9,96^{\mathrm{b}} \pm 0,76$ & $14,64^{\mathrm{a}} \pm 0,30$ & $12,89^{\mathrm{a}} \pm 0,08$ \\
Japonesa & $11,01^{\mathrm{a}} \pm 0,78$ & $14,18^{\mathrm{b}} \pm 0,10$ & $12,94^{\mathrm{a}} \pm 0,35$ \\
\hline MG & 10,48 & 14,41 & 12,91 \\
DMS & 0,93 & 0,33 & 0,44 \\
CV (\%) & 3,91 & 1,01 & 1,5 \\
Fcal. & $9,87^{*}$ & $14,72^{*}$ & $0,11^{\text {ns }}$ \\
\hline
\end{tabular}

Fonte: Dados da pesquisa.

Legenda: MG = Média geral; DMS = Desvio médio significativo; CV = Coeficiente de variação; \pm = Desvio padrão; Fcal = F calculado. Médias seguidas de diferentes letras na coluna diferem estaticamente a $5 \%$ de probabilidade, pelo teste de Tukey; ns = não significativo, ${ }^{*}=$ significativo a $5 \%$ pelo teste $\mathrm{F}$. 
na clara e na gema. Costa et al. (2008) observaram $16,30 \%$ de proteína em gemas de ovos de poedeira. Sartori et al. (2009) encontraram, em gemas cruas e cozidas de ovos de galinha, teores de proteínas de $11,19 \pm 0,30 \mathrm{~g} / 100 \mathrm{~g}$ e $11,93 \pm 0,79 \mathrm{~g} / 100 \mathrm{~g}$, respectivamente. Salvador e Santa (2002) determinaram teores de proteínas em diferentes tipos de ovos (mix) e encontraram os seguintes resultados: 14,92 $\pm 1,18 \%$ (ovos de codorna); $12,51 \pm 0,25 \%$ (ovos brancos); $12,64 \pm 2,64 \%$ (ovos vermelhos de galinha de granja) e $12,77 \pm 0,69 \%$ (ovos vermelhos de galinha caipira).

\section{Conclusão}

Concluiu-se que existem diferenças significativas entre as características físicas e químicas de ovos de codorna japonesa e americana. Os ovos da linhagem americana apresentaram maiores massas, diâmetros longitudinal e transversal, maior luminosidade e cromaticidade na clara, gema e mix, além de maior teor de proteína na gema. Por outro lado, nos ovos da linhagem japonesa, verificou-se $\mathrm{pH}$ mais elevado na clara e na gema e a maior Aw na gema, bem como maior teor de proteína na clara do que nos ovos da linhagem americana.

\section{Referências}

ASSOCIATION OF OFFICIAL ANALYTICAL CHEMISTS AOAC. Official methods of analysis. 16th ed. Washington, D.C: [s.n.], 1995.

ALBINO, L. F. T.; BARRETO, S. L. T. Codornas: criação de codornas para produção de ovos e carne. Viçosa, MG: Aprenda Fácil, 2003.

ALLEONI, A. C. C.; ANTUNES, A. J. Perfil de textura e umidade espremível de géis do albume de ovos recobertos com soro de leite. Ciência e Tecnologia de Alimentos, v. 25 , n. 1 , p. 153-157, 2005.

BAPTISTA, R. F. Avaliação da qualidade interna de ovos de codorna (Coturnix coturnix japonica) em função da variação da temperatura de armazenamento. 2002. 99 f. Dissertação (Mestrado em Medicina Veterinária) Universidade Federal Fluminense, Niterói, 2002.
BRASIL. Ministério da Agricultura e do Abastecimento. Secretaria de Defesa Agropecuária. Departamento de Inspeção de Produtos de Origem Animal. Regulamento da inspeção industrial e sanitária de produtos de origem animal (RIISPOA). Aprovado pelo Decreto n. 30.691, 29/03/52, alterado pelos Decretos n. 1255 de 25/06/62, 1236 de 02/09/94, 1812 de 08/02/96 e 2244 de 04/06/97. Brasília, 1997. p. 241.

CARVALHO, F. B. et al. Qualidade interna e da casca para ovos de poedeiras comerciais de diferentes linhagens e idades. Ciência Animal Brasileira, v. 8, n. 1, p. 25-29, 2007.

COSTA, F. G. P. et al. Influência do óleo de linhaça sobre o desempenho e a qualidade dos ovos de poedeiras semipesadas. Revista Brasileira de Zootecnia, v. 37, n. 5, p. 861-868, 2008.

FERREIRA, C. D.; PENA, R. S. Comportamento higroscópico da farinha de pupunha (Bactris gasipaes). Ciência e Tecnologia de Alimentos, v. 23, n. 2, p. 251-255, 2003.

FREITAS, L. W. et al. Aspectos qualitativos de ovos comerciais submetidos a diferentes condições de armazenamento. Revista Agrarian, v. 4, n. 11, p. 66-72, 2011.

HENCKEN, H. Chemical and Physiological behavior of feed carotenoids and their effects on pigmentation. Poultry Science, v. 71, n. 4, p. 711-717, 1992.

HOFFMANN, F. L. Fatores limitantes à proliferação de microorganismos em alimentos. Brasil Alimentos, n. 9, p. 23-30, 2001.

INSTITUTO ADOLFO LUTZ. Normas analíticas, métodos químicos e físicos para análises de alimentos. 4. ed. São Paulo: Instituto Adolfo Lutz, 2008.

LEANDRO, N. S. M. et al. Aspectos de qualidade interna e externa de ovos comercializados em diferentes estabelecimentos na região de Goiânia. Ciência Animal Brasileira, v. 6, n. 2, p. 71-78, 2005.

LUCOTTE, G. La codorniz cría y explotación. Madrid: Mundi-Prensa, 1976.

MINE, Y. Recents advances in the understanding of egg white protein functionally. Trends in Food Science \& Technology, v. 6, n. 7, p. 225-232, 1995.

MOURA, A. M. A. et al. Características sensoriais de ovos de codornas japonesas (Coturnix japonica Temminck e Schlegel, 1849) suplementadas com pigmentantes sintéticos e selenometionina. Ciência e Agrotecnologia, v. 33, n. 6, p. 1594-1600, 2009. 
MOURA, A. M. A. et al. Desempenho e qualidade do ovo de codornas japonesas alimentadas com rações contendo sorgo. Revista Brasileira de Zootecnia, v. 39, n. 12, p. 2697-2702, 2010a.

MOURA, G. S.; BARRETO, S. L. T.; LANNA, E. A. T. Efeito da redução da densidade energética de dietas sobre as características do ovo de codorna japonesa. Revista Brasileira de Zootecnia, v. 39, n. 6, p. 1266-1271, 2010 b.

PANDA, B.; SINGH, R. P. Developments in processing quail meat and eggs. World's Poultry Science Journal, v. 46, n. 3, p. $220-234,1990$.

PICCININ, A. et al. Técnicas de conservação da qualidade de ovos de codornas (Coturnix coturnix japonica). Revista Científica de Produção Animal, v. 7, n. 2, p. 52-59, 2005.

SALVADOR, M.; SANTA, P. D. Teores de macronutrientes e de colesterol em diferentes tipos de ovos. Boletim do Centro de Pesquisa de Processamento de Alimentos, v. 20, n. 1, p. 133-140, 2002.

SARTORI, E. V. et al. Concentração de proteínas em gemas de ovos de poedeiras (Gallus gallus) nos diferentes ciclos de postura e sua interferência na disponibilidade do ferro. Ciência e Tecnologia de Alimentos, v. 29, n. 3, p. 481487, 2009.

SEIBEL, N. F.; SOARES, L. A. S. Efeito do resíduo de pescado sobre as características físicas e químicas de ovos de codornas armazenados em diferentes períodos. Semina: Ciências Agrárias, v. 25, n. 1, p. 35-44, 2004.
SEIBEL, N. F. et al. Qualidade física e química de ovos de codornas alimentadas com dietas modificadas. Revista do Instituto Adolfo Lutz, v. 64, n. 1, p. 58-64, 2005.

SGARBIERI, V. C. Proteínas em alimentos protéicos. São Paulo: Varela, 1996.

SOBRAL, F. E. S. et al. Caracterização do consumidor de ovos de codorna no município de Patos-PB. Agropecuária Científica no Semi-Árido, v. 5, n. 1, p. 62-66, 2009.

SOUZA, H. B. A.; SOUZA, P. A. Efeito da temperatura de estocagem sobre a qualidade interna de ovos de codorna armazenados durante 21 dias. Alimentos e Nutrição, v. 6, n. 1, p. 7-13, 1995.

VADEHRA, D. V.; NATH, K. R. Eggs as a source of protein. Critical Reviews in Food Technology, v. 4, n. 1, p. 193308, 1973.

Recebido: $18 / 07 / 2011$

Received: 07/18/2011

Aprovado: 24/10/2011

Approved: 10/24/2011 